\title{
Systematic review of dexketoprofen in acute and chronic pain R Andrew Moore ${ }^{* \dagger}$ and Jodie Barden ${ }^{\dagger}$
}

Address: Pain Research and Nuffield Department of Anaesthetics, University of Oxford, Level 6, West Wing, John Radcliffe Hospital, Oxford OX3 9DU, UK

Email: R Andrew Moore* - andrew.moore@pru.ox.ac.uk; Jodie Barden - jodie.barden@balliol.ox.ac.uk

* Corresponding author †Equal contributors

Published: 31 October 2008

BMC Clinical Pharmacology 2008, 8:I I doi: 10.1 186/1472-6904-8-I I

This article is available from: http://www.biomedcentral.com/I472-6904/8/II

(c) 2008 Moore and Barden; licensee BioMed Central Ltd.

This is an Open Access article distributed under the terms of the Creative Commons Attribution License (http://creativecommons.org/licenses/by/2.0), which permits unrestricted use, distribution, and reproduction in any medium, provided the original work is properly cited.
Received: 25 March 2008

Accepted: 31 October 2008

\begin{abstract}
Background: Dexketoprofen, an NSAID used in the management of acute and chronic pains, is licensed in several countries but has not previously been the subjected of a systematic review. We used published and unpublished information from randomised clinical trials (RCTs) of dexketoprofen in painful conditions to assess evidence on efficacy and harm.
\end{abstract}

Methods: PubMed and Cochrane Central were searched for RCTs of dexketoprofen for pain of any aetiology. Reference lists of retrieved articles and reviews were also searched. Menarini Group produced copies of published and unpublished studies (clinical trial reports). Data were abstracted into a standard form. For studies reporting results of single dose administration, the number of patients with at least $50 \%$ pain relief was derived and used to calculate the relative benefit (RB) and number-needed-to-treat (NNT) for one patient to achieve at least 50\% pain relief compared with placebo.

Results: Thirty-five trials were found in acute pain and chronic pain; 6,380 patients were included, 3,381 receiving dexketoprofen. Information from 16 trials (almost half the total patients) was obtained from clinical trial reports from previously unpublished trials or abstracts. Almost all of the trials were of short duration in acute conditions or recent onset pain.

All 12 randomised trials that compared dexketoprofen (any dose) with placebo found dexketoprofen to be statistically superior. Five trials in postoperative pain yielded NNTs for 12.5 $\mathrm{mg}$ dexketoprofen of 3.5 (2.7 to 4.9), $25 \mathrm{mg}$ dexketoprofen of 3.0 (2.4 to 3.9), and $50 \mathrm{mg}$ dexketoprofen of 2.1 ( 1.5 to 3.5). In 29/30 active comparator trials, dexketoprofen at the dose used was at least equivalent in efficacy to comparator drugs. Adverse event withdrawal rates were low in postoperative pain and somewhat higher in trials of longer duration; no serious adverse events were reported.

Conclusion: Dexketoprofen was at least as effective as other NSAIDs and paracetamol/opioid combinations. While adverse event withdrawal was not different between dexketoprofen and comparator analgesics, the different conditions and comparators studies precluded any formal analysis. Exposure was limited, and no conclusions could be drawn about safety in terms of serious adverse events like gastrointestinal bleeding or cardiovascular events. 


\section{Introduction}

Racemic ketoprofen is used as an analgesic and an antiinflammatory agent, and is one of the most potent in vitro inhibitors of prostaglandin synthesis, but is also implicated as having an association with higher risk of serious gastrointestinal bleeding events than other NSAIDs $[1,2]$. The analgesic effect is due to the $\mathrm{S}(+)$-enantiomer (dexketoprofen), while the R(-)-enantiomer is devoid of analgesic activity [3]. Because the R(-)-enantiomer does appear to have ulcerogeneic activity, at least in the rat $[3,4]$, the implication is that use of dexketoprofen alone should produce equivalent analgesia to double-dose ketoprofen, but at lower risk of harm. At least one case-control study in Spain appears to confirm a lower rate of serious gastrointestinal harm with dexketoprofen than ketoprofen, but with overlapping confidence intervals and small numbers of events [2]. Other authorities regard the approach of using an active enantiomer as a tromethamine salt as attractive on theoretical grounds [4].

Formulation is important, especially the use of the trometamol salt for rapid absorption [3]. In healthy volunteers absorption of dexketoprofen from dexketoprofen trometamol capsules was similar to ketoprofen, while the extent of absorption of dexketoprofen free acid was significantly lower than that for ketoprofen [5]. Dexketoprofen trometamol showed the most rapid absorption rate, with highest maximum plasma concentration and shortest time to maximum values, while ketoprofen had an intermediate absorption rate, and dexketoprofen free acid the slowest absorption rate. After repeated-dose administration of dexketoprofen trometamol, the pharmacokinetic parameters were similar to those obtained after single doses, indicating that no drug accumulation occurred [5]. Food slowed absorption of dexketoprofen, even from the trometamol salt [6].

Dexketoprofen is licensed in a number of countries around the world. Oral dexketoprofen was approved in the European Countries through a Mutual Recognition Procedure on 13th February 1998 and the injectable formulation on 25th October 2002. Dexketoprofen has not been subjected to the scrutiny of a systematic review, and not reviewed at all since preclinical and clinical development studies were reviewed over a decade ago [7]. We sought to obtain published and unpublished information from randomised clinical trials of dexketoprofen to assess the available evidence on efficacy and harm.

Systematic reviews are useful for pulling together all the studies on a topic - here randomised, double blind comparative trials of dexketoprofen in painful conditions. By assessing trial quality and validity $[8,9]$ it is possible to eliminate trials likely to be biased, and biased trials are much more likely to over-estimate treatment effects. Accu- mulating many similar trials together reduces the possibility of variation in efficacy estimates because of the random play of chance, and should improve assessment of harm.

\section{Methods}

We searched PubMed, and Cochrane Central up to October 2008 for randomised controlled trials using dexketoprofen to treat pain of any aetiology. The detailed search strategy included use of the drug name dexketoprofen anywhere in an article, together with the publication descriptor of randomised trial; this was modified for the different databases. Reference lists of retrieved articles and reviews were also searched for relevant trials. In addition, Menarini Group also produced copies of published and unpublished studies, the latter in the form of clinical trial reports.

For inclusion, trials had to be at least randomised, and use dexketoprofen to treat adult patients with pain of any origin. Trials had to have a minimum of 10 patients per treatment arm, and at least one dose of dexketoprofen given by any route of administration, at any dose, and with any comparator.

The abstracts were read, and potentially useful reports retrieved in full paper copy. No information was taken from posters or abstracts unless supplemented by details from a clinical trial report. Decisions on inclusion or exclusion of trials, assessment of trial quality and validity and all data extraction were made independently by both reviewers, with discrepancies resolved by consensus.

Methodological quality of included studies was assessed using the validated 5-point Oxford quality scale [8] utilising reporting of randomisation, blinding and withdrawals. The maximum score possible was 5 points, and no study could be included with fewer than 2 points (one for randomisation and one for blinding). Study validity was assessed using the validated Oxford Pain Validity Scale (OPVS) 16-point scale [9]. Only trials that were both randomised and double blind were used for calculation of numbers needed to treat.

Data were abstracted into a standard form. Information was extracted from the trials according to painful condition, with details of drugs, dose, route of administration, patient numbers, treatment and observation schedule, outcomes measured, and main efficacy and safety results.

For studies reporting results of single dose administration we sought to the outcome of at least $50 \%$ pain relief. For each report, mean TOTPAR (total pain relief) or SPID (summed pain intensity difference) for active and placebo groups were converted to \%maxTOTPAR or \%maxSPID 
by division into the calculated maximum value [10]. The proportion of patients in each treatment group who achieved at least 50\%maxTOTPAR was calculated using verified equations [11-13]. These proportions were then converted into the number of patients achieving at least $50 \%$ maxTOTPAR by multiplying by the total number of patients in the treatment group. Information on the number of patients with at least 50\%maxTOTPAR for active treatment and placebo was then used to calculate relative benefit (RB) and number needed-to-treat (NNT). Pain measures accepted for the calculation of TOTPAR or SPID were:

- 5-point categorical pain relief (PR) scales with comparable wording to "none, slight, moderate, good or complete"

- 4-point categorical pain intensity (PI) scales with comparable wording to "none, mild, moderate, severe"

- Visual analogue scales (VAS) for pain relief

- VAS for pain intensity

- 5-point categorical global scale with the wording "poor, fair, good, very good, excellent" [14]

Other measures of pain relief were abstracted where reported and appropriate. Secondary outcomes were withdrawals (all cause, lack of efficacy and adverse events) and adverse events (patients with at least one adverse event, serious adverse events, and specific adverse events). We anticipated that reporting of adverse events would vary between trials with regard to the terminology used, method of ascertainment, and categories reported (e.g. occurring in $\geq 5 \%$ of patients or where there was a statistically significant difference between treatment groups).

Guidelines for quality of reporting of meta-analyses were followed where appropriate [15]. The prior intention was to pool data where there was clinical and methodological homogeneity, with similar patients, dose, duration, outcomes, and comparators, but not where numbers of events were small, and random chance could dominate effects of treatment [16]. Homogeneity tests and funnel plots, though commonly used in meta-analysis, were not used here because they have been found to be unreliable $[17,18]$. Instead clinical homogeneity was examined graphically [19]. Relative benefit (or risk) and numberneeded-to-treat or harm (NNT or NNH) were calculated with $95 \%$ confidence intervals. Relative benefit or risk was calculated using a fixed effects model [20], with no statistically significant difference between treatments assumed when the $95 \%$ confidence intervals included unity. We added 0.5 to treatment and comparator arms of trials in which at least one arm had no events. Number-needed-totreat (or harm) was calculated by the method of Cook and Sackett [21] using the pooled number of observations only when there was a statistically significant difference of relative benefit or risk (where the confidence interval did not include 1). There was a prior intention to carry out sensitivity analyses for high versus low trial quality $(<3$ vs $\geq 3$ ), dose, and condition. Information would be reported with any number of patients, but not regarded unless there was a minimum of two trials or 250 patients [16].

\section{Results}

Thirty-five trials were found in acute and chronic pain, 32 of which had reporting quality of $3 / 5$ or better and 30 of which had OPVS score of at least 9/16 (Table 1). Ten trials had individual group sizes of 100 patients or more. The total number of patients was 6,380, of whom 3381 received dexketoprofen (Table 1 ). More patients were in trials of oral therapies $(4,249$ total, 2,270 on dexketoprofen) than trials of intramuscular or intravenous therapies (2,131 total, 1,111 on dexketoprofen). Information from 16 trials $(46 \%)$ with 3,253 patients $(51 \%)$ was obtained from clinical trial reports from previously unpublished trials, or trials published only as abstracts. All 16 clinical trial reports had a quality score of at least $3 / 5$ and an OPVS score of at least 9/16. Almost all of the trials were of short duration in acute conditions, or for recent onset pain. Only two, in osteoarthritis, investigated efficacy in chronic painful conditions.

All 12 randomised trials that compared dexketoprofen, at any dose, with placebo found dexketoprofen to be statistically superior (Table 1). More common was a comparison of dexketoprofen with an active comparator, which happened in 30 trials. In 29 of these 30 trials, dexketoprofen at the dose used was at least equivalent in efficacy to the comparator drugs with known analgesic efficacy.

\section{Single and multiple dose trials in dental pain}

Seven randomised trials [22-29] examined the analgesic efficacy of oral dexketoprofen in 994 patients studied in the third molar extraction pain model, 618 of whom received dexketoprofen (Additional file 1). One trial was published as an abstract [29], with data taken from a clinical trial report [23]. Six of the seven trials were both randomised and double blind, and had quality scores of 4 or 5 of the maximum 5 points and had OPVS scores of at least 9/16. One open trial [27] scored only 1 out of 5 .

Three good quality trials were standard pain models reporting pain intensity or pain relief for four to six hours after the initial dose, had patients with moderate or severe pain at entry, and measured pain intensity and pain relief over six hours $[24,25,28]$. In these three trials dexketoprofen at doses of 10 or $12.5 \mathrm{mg}$ (Figure 1), 20 or $25 \mathrm{mg}$ (Fig- 
Table I: Summary table of randomised trials included in the review

\begin{tabular}{|c|c|c|c|c|c|c|c|c|}
\hline \multirow[b]{2}{*}{$\begin{array}{l}\text { Pain } \\
\text { condition }\end{array}$} & \multicolumn{4}{|c|}{ Number of: } & \multicolumn{2}{|c|}{ Number of patients } & \multirow[b]{2}{*}{$\begin{array}{l}\text { Better than } \\
\text { placebo/total } \\
\text { comparisons }\end{array}$} & \multirow[b]{2}{*}{$\begin{array}{c}\text { At least equivalent } \\
\text { to effective } \\
\text { analgesic/total } \\
\text { comparisons }\end{array}$} \\
\hline & Studies & $\begin{array}{c}\text { Studies } \\
\text { with QS } \\
\geq 3 / 5\end{array}$ & $\begin{array}{l}\text { Studies with } \\
\text { OPVS } \geq 9 / 16\end{array}$ & $\begin{array}{c}\begin{array}{c}\text { Trials of } \\
\text { group size } \geq \\
100\end{array}\end{array}$ & In total & $\begin{array}{c}\text { Given } \\
\text { dexketoprofen }\end{array}$ & & \\
\hline Dental pain & 7 & 6 & 6 & 0 & 994 & 618 & $4 / 4$ & $3 / 4$ \\
\hline Postsurgical & 13 & 11 & 11 & 2 & 2185 & 1022 & $7 / 7$ & ||$/||$ \\
\hline Renal colic & 3 & 3 & 3 & 3 & 838 & 526 & & $3 / 3$ \\
\hline $\begin{array}{l}\text { Gynaecologic } \\
\text { pain }\end{array}$ & 2 & 2 & 1 & 1 & 350 & 200 & $1 / 1$ & $2 / 2$ \\
\hline $\begin{array}{l}\text { Lower limb } \\
\text { injury }\end{array}$ & I & 1 & I & 0 & 122 & 65 & & $1 / 1$ \\
\hline Ankle sprain & I & 1 & 1 & 1 & 209 & 106 & & $\mathrm{I} / \mathrm{I}$ \\
\hline $\begin{array}{l}\text { Acute bone } \\
\text { pain in cancer }\end{array}$ & I & 1 & 1 & 0 & 115 & 57 & & $\mathrm{I} / \mathrm{I}$ \\
\hline $\begin{array}{l}\text { Acute low } \\
\text { back pain }\end{array}$ & 5 & 5 & 5 & 3 & 1267 & 635 & & $5 / 5$ \\
\hline OA/RA & 2 & 2 & 2 & 0 & 300 & 152 & & $2 / 2$ \\
\hline Total & 35 & 32 & 31 & 10 & 6380 & 3381 & $12 / 12$ & $29 / 30$ \\
\hline
\end{tabular}

$\mathrm{QS}=$ quality score; OPVS = Oxford Pain Validity Score; OA = osteoarthritis; RA = rheumatoid arthritis

ure 2), and $50 \mathrm{mg}$ were all significantly superior to placebo, with NNTs for at least $50 \%$ pain relief over six hours compared with placebo of 3.0 (2.3 to 4.4), 2.6 (2.0 to 3.5 ), and 2.1 (1.5 to 3.5 ) respectively (Table 2 ). One trial [28] used ketoprofen $50 \mathrm{mg}$, and that was also significantly better than placebo. The one other trial that used placebo [26] reported data at eight hours, and appeared to measure pain scores after use of remedication. Despite that, dexketoprofen $25 \mathrm{mg}$ was significantly better than placebo.

Dexketoprofen $12.5 \mathrm{mg}$ and $25 \mathrm{mg}$ were both superior to dipyrone $575 \mathrm{mg}$ in the single dose phase of a multiple dose trial [22]. There was no difference between use of pre and postsurgical dexketoprofen in another trial $[23,29]$. The final trial [27] compared dexketoprofen $25 \mathrm{mg}$ with ibuprofen $600 \mathrm{mg}$, but no interpretation could be made in this case because it included patients with mild pain which is known to desensitise pain trials.

\section{Single and multiple dose trials in postsurgical pain}

Thirteen randomised trials [30-43] examined the analgesic efficacy of dexketoprofen in 2135 patients studied in postsurgical pain, 997 of whom received dexketoprofen (Additional file 2). One trial was published as an abstract [31] with data taken from a clinical trial report [42]. Twelve of the 13 trials were both randomised and double blind, and 11 had quality scores of three or more of the maximum 5 points and at least 9 on an OPVS (Table 1). Eight trials (1212 patients) used oral dexketoprofen and four (923 patients) intramuscular or intravenous dexketo- profen. Eight of the 13 trials were in major orthopaedic surgery (mainly knee and hip surgery), the others involving arthroscopy, bunionectomy, hernias, abdominal hysterectomy, and abdominal surgery.

Two good quality trials were standard pain models reporting pain intensity or pain relief for four to six hours after the initial dose, had patients with moderate or severe pain at entry, and measured pain intensity and pain relief over six hours $[32,34]$. In these trials oral dexketoprofen at doses of 10 or $12.5 \mathrm{mg}$ (Figure 1) and 20 or $25 \mathrm{mg}$ (Figure 2) were significantly superior to placebo, with NNTs for at least $50 \%$ pain relief over six hours compared with placebo of 4.4 (2.8 to 9.7) and 3.7 (2.5 to 7.0) respectively (Table 2). Four of the nine oral trials used placebo, and in these dexketoprofen was significantly better than placebo on at least one measure in three trials [34,39,43], but not in the fourth [32]. Ketoprofen $50 \mathrm{mg}$ was not significantly better than placebo in the two trials that used it $[32,34]$.

Where there was an active comparator, dexketoprofen 25 mg appeared to be equivalent to tramadol $50 \mathrm{mg}[42,33]$, diclofenac $50 \mathrm{mg}$ [36], and paracetamol $500 \mathrm{mg}$ plus codeine $22.5 \mathrm{mg}$ [38]. Three trials compared dexketoprofen $25 \mathrm{mg}$ with ketoprofen $50 \mathrm{mg}$; while there was no difference in one small trial [41], ketoprofen appeared to be less effective in two others [32,34].

Two trials $[35,40]$ used intramuscular administration of dexketoprofen at doses of $25 \mathrm{mg}$ or $50 \mathrm{mg}$ twice a day, and two [30,37] intravenous administration of $50 \mathrm{mg}$ three 
Table 2: Results of single dose trials in dental and postsurgical pain for comparison of dexketoprofen with placebo, and dexketoprofen with ketoprofen

Dexketoprofen versus placebo

\begin{tabular}{|c|c|c|c|c|c|c|}
\hline \multirow[b]{2}{*}{$\begin{array}{l}\text { Dexketoprofen dose } \\
(\mathrm{mg})\end{array}$} & \multicolumn{2}{|c|}{ Number of } & \multicolumn{2}{|c|}{$\begin{array}{c}\text { Percent of patients with at least } 50 \% \text { pain } \\
\text { relief }\end{array}$} & \multirow[b]{2}{*}{$\begin{array}{l}\text { Relative benefit } \\
\quad(95 \% \mathrm{Cl})\end{array}$} & \multirow[b]{2}{*}{ NNT $(95 \% \mathrm{Cl})$} \\
\hline & Trials & Patients & Dexketoprofen & Placebo & & \\
\hline \multicolumn{7}{|l|}{ All trials } \\
\hline $10 / 12.5 \mathrm{mg}$ & 5 & 462 & 45 & 17 & $3.4(2.2$ to 5.6$)$ & 3.5 (2.7 to 4.9$)$ \\
\hline $20 / 25 \mathrm{mg}$ & 5 & 455 & 50 & 17 & $3.9(2.4$ to 6.3$)$ & 3.0 (2.4 to 3.9$)$ \\
\hline $50 \mathrm{mg}$ & 1 & 67 & 56 & 8 & 6.7 (1.7 to 26$)$ & 2.1 (1.5 to 3.5$)$ \\
\hline \multicolumn{7}{|l|}{ Dental } \\
\hline $10 / 12.5 \mathrm{mg}$ & 3 & $26 I$ & 47 & 13 & 3.5 (2.2 to 5.6$)$ & $3.0(2.3$ to 4.4$)$ \\
\hline $20 / 25 \mathrm{mg}$ & 3 & 254 & 52 & 13 & 3.9 (2.4 to 6.3$)$ & 2.6 (2.0 to 3.5$)$ \\
\hline $50 \mathrm{mg}$ & 1 & 67 & 56 & 8 & $6.7(1.7$ to 26$)$ & 2.1 (1.5 to 3.5$)$ \\
\hline \multicolumn{7}{|l|}{ Postsurgical } \\
\hline $10 / 12.5 \mathrm{mg}$ & 2 & 201 & 43 & 21 & 2.1 (1.4 to 3.3$)$ & 4.4 (2.8 to 9.7$)$ \\
\hline $20 / 25 \mathrm{mg}$ & 2 & 201 & 47 & 21 & $2.3(1.5$ to 3.6$)$ & $3.7(2.5$ to 7.0$)$ \\
\hline
\end{tabular}

Dexketoprofen versus ketoprofen

\begin{tabular}{|c|c|c|c|c|c|c|}
\hline \multirow[b]{2}{*}{$\begin{array}{l}\text { Dexketoprofen/ } \\
\text { ketoprofen dose (mg) }\end{array}$} & \multicolumn{2}{|c|}{ Number of } & \multicolumn{2}{|c|}{$\begin{array}{l}\text { Percent of patients with at least } 50 \% \text { pain } \\
\text { relief }\end{array}$} & \multirow[b]{2}{*}{$\begin{array}{l}\text { Relative benefit } \\
(95 \% \mathrm{Cl})\end{array}$} & \multirow[b]{2}{*}{ NNT $(95 \% \mathrm{Cl})$} \\
\hline & Trials & Patients & Dexketoprofen & Ketoprofen & & \\
\hline \multicolumn{7}{|l|}{ All trials } \\
\hline 12.5 vs 50 & 3 & 287 & 44 & 35 & $0.8(0.5$ to I. 2$)$ & not calculated \\
\hline 25 vs 50 & 3 & 284 & 51 & 35 & I.I (0.7 to I.5) & not calculated \\
\hline 50 vs 100 & 1 & 247 & 82 & 77 & I.I (0.9 to I.2) & not calculated \\
\hline $25 / 50$ vs $50 / 100$ & 4 & 531 & 65 & 54 & I.2(I.I to I.4) & $8.8(5.1$ to 33$)$ \\
\hline
\end{tabular}

times a day, or $50 \mathrm{mg}$ twice a day. Time intervals between doses were 6-8 h and 12 hours in the different studies. Three $[35,37,40]$ made a comparison with placebo, and in all three doses of dexketoprofen were significantly better than placebo on at least one measure of efficacy. All four trials had an active comparator, and dexketoprofen at the dose studied was at least as effective as ketoprofen $100 \mathrm{mg}$ [30,40], tramadol $100 \mathrm{mg}$ [37], and diclofenac $75 \mathrm{mg}$ twice a day [35]. There was a suggestion of somewhat better efficacy between three and eight hours, and lower morphine requirements, than diclofenac $75 \mathrm{mg}$ twice a day [35].

Overall results of single dose dexketoprofen in acute pain, and comparison with ketoprofen

Combining three third molar extraction and two postsurgical trials (Table 2) gave NNTs for at least 50\% pain relief for $12.5 \mathrm{mg}$ dexketoprofen of 3.5 (2.7 to 4.9), $25 \mathrm{mg}$ dexketoprofen of 3.0 (2.4 to 3.9), and 50 mg dexketoprofen of 2.1 (1.5 to 3.5). The overlapping confidence intervals and formal testing [44] for difference between NNTs showed no statistical difference between $12.5 \mathrm{mg}$ and 25 mg doses.

Several trials used both dexketoprofen and ketoprofen. Table 2 also shows the comparisons between $12.5 \mathrm{mg}$ and $25 \mathrm{mg}$ dexketoprofen and $50 \mathrm{mg}$ ketoprofen, and $50 \mathrm{mg}$ dexketoprofen and $100 \mathrm{mg}$ ketoprofen. While the proportion of patients achieving at least $50 \%$ pain relief was consistently higher with dexketoprofen, this did not reach statistical significance with any comparison. However, when $25 \mathrm{mg}$ or $50 \mathrm{mg}$ dexketoprofen were compared with $50 \mathrm{mg}$ or $100 \mathrm{mg}$ ketoprofen (that is, double the dose, Figure 3), statistical significance was achieved, with a number needed to treat of 8.8 (5.1 to 33). That means that for every nine persons treated with $25 \mathrm{mg}$ or $50 \mathrm{mg}$ dexketo- 
At least $50 \%$ pain relief with dexketoprofen $10 / 12.5 \mathrm{mg}$

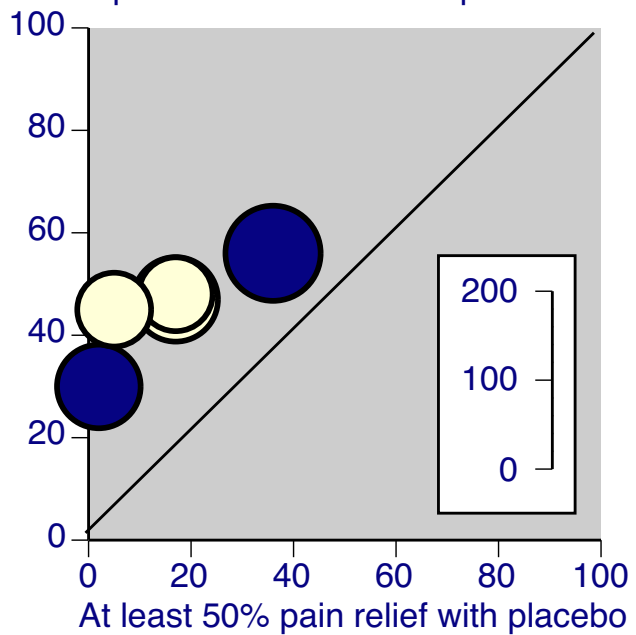

Figure I

L'Abbé plot of individual trials of dexketoprofen $10 /$ $12.5 \mathrm{mg}$ compared with placebo in dental and postsurgical pain. Inset scale shows size of trial. Light symbols = dental trials, dark symbols $=$ postsurgical trials .

At least $50 \%$ pain relief with dexketoprofen $20 / 25 \mathrm{mg}$

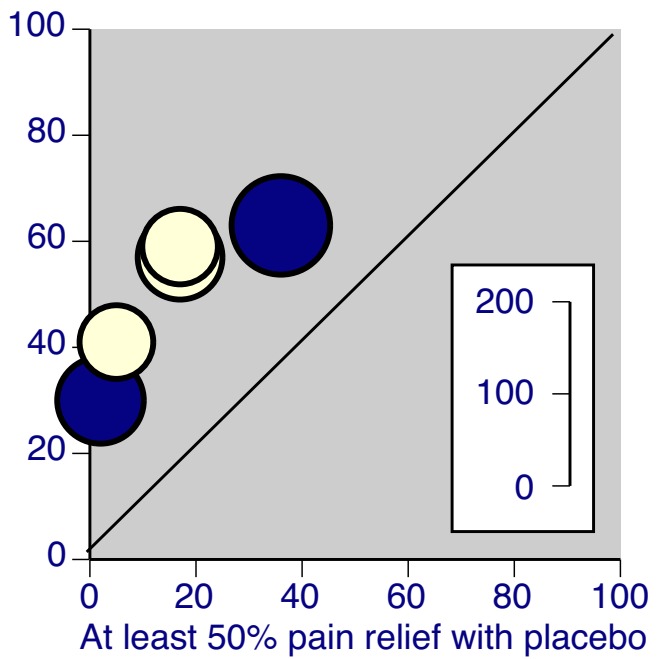

Figure 2

L'Abbé plot of individual trials of dexketoprofen 20/ $\mathbf{2 5} \mathbf{~ m g}$ compared with placebo in dental and postsurgical pain. Inset scale shows size of trial. Light symbols = dental trials, dark symbols $=$ postsurgical trials.

\section{At least $50 \%$ pain relief with dexketoprofen}

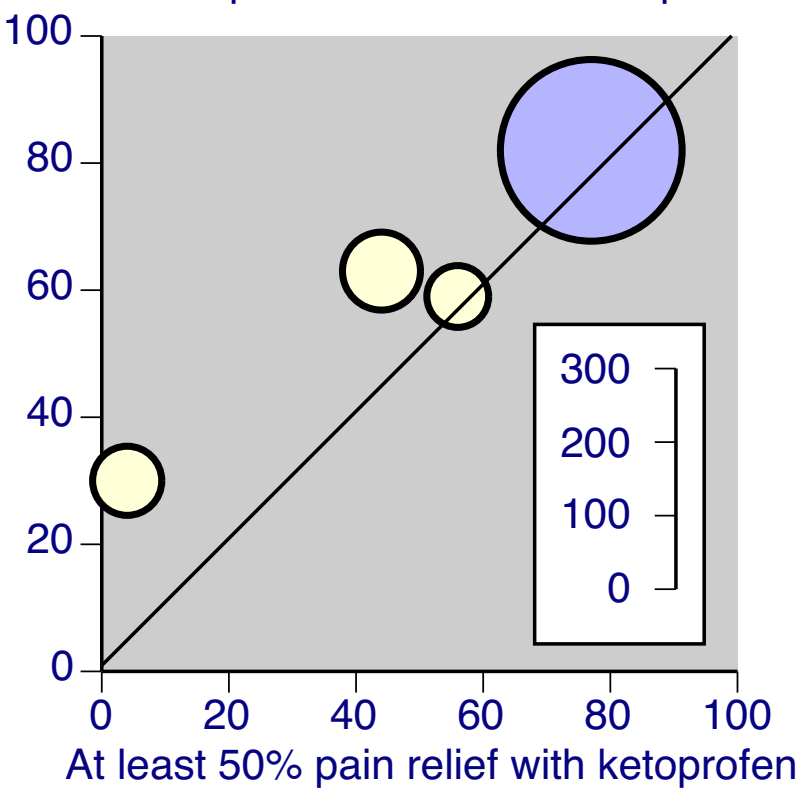

Figure 3

L'Abbé plot of individual trials of dexketoprofen compared with double dose of ketoprofen in dental and postsurgical pain. Inset scale shows size of trial. Light symbols $=25 \mathrm{mg}$ vs $50 \mathrm{mg}$, dark symbols $=50 \mathrm{mg}$ vs $100 \mathrm{mg}$.

profen, one more would have at least $50 \%$ pain relief than if the same nine patients were treated with ketoprofen 50 $\mathrm{mg}$ or $100 \mathrm{mg}$.

\section{Single dose trials in pain of renal colic}

Three randomised trials [45-47] examined the analgesic efficacy of dexketoprofen $25 \mathrm{mg}$ and $50 \mathrm{mg}$ intramuscularly, and $25 \mathrm{mg}$ and $50 \mathrm{mg}$ intravenously, in 838 patients studied in pain of renal colic, 526 of whom received dexketoprofen (Additional file 3). All of the trials were both randomised and double blind, all had quality scores of three or more of the maximum 5 points and at least 9 points on an OPVS. One trial [45] used intramuscular dexketoprofen and two $[46,47]$ intravenous dexketoprofen.

None of the trials had a placebo control, and all examined efficacy over six hours after a single dose $\mathrm{n}$ pain of moderate or severe intensity. Intramuscular dexketoprofen 25 $\mathrm{mg}$ and $50 \mathrm{mg}$ were indistinguishable from intramuscular dipyrone $2000 \mathrm{mg}$ [45]. Intravenous dexketoprofen 25 $\mathrm{mg}$ or $50 \mathrm{mg}$ were indistinguishable from intravenous dipyrone $2000 \mathrm{mg}$ or more [46], and intravenous dexketoprofen $50 \mathrm{mg}$ was indistinguishable from intravenous ketoprofen $100 \mathrm{mg}$ [47]. 


\section{Multiple dose trials in acute low back pain}

Five trials [48-53] examined short-term use of dexketoprofen in acute low back pain, generally over about a week (Additional file 4); one was published in German [50], but data were taken from a clinical trial report [49]. All of the trials were both randomised and double blind, all had quality scores of three or more of the maximum 5 points and at least 9 points on an OPVS. One shorter trial compared $50 \mathrm{mg}$ twice-daily intramuscular dexketoprofen with $75 \mathrm{mg}$ diclofenac in almost 400 patients [48]. Four oral comparisons of dexketoprofen $25 \mathrm{mg}$ three times daily over 4-7 days in patients with pain of acute onset back pain of at least moderate severity showed similar efficacy to diclofenac $150 \mathrm{mg}$ daily [51], tramadol $150 \mathrm{mg}$ daily $[49,52]$, and paracetamol $800 \mathrm{mg}$ plus dextropropoxyphene $60 \mathrm{mg}$ daily [53].

\section{Single and multiple dose trials in other acute painful conditions}

Five randomised trials [54-58] have examined the analgesic efficacy in other acute painful conditions in 796 patients, 428 of whom received oral dexketoprofen, mainly at $25 \mathrm{mg}$ (Additional file 5). All of the trials were both randomised and double blind, all had quality scores of three or more of the maximum 5 points and at least 9 points on an OPVS. Only one trial [54] was placebo controlled, and looked at efficacy of $12.5 \mathrm{mg}$ and $25 \mathrm{mg}$ of dexketoprofen in comparison with $50 \mathrm{mg}$ ketoprofen in 52 women with dysmenorrhoea; all three active treatments were superior to placebo, but not different one from another.

Dexketoprofen $25 \mathrm{mg}$ orally was found to be superior to injections of mepivacaine into the uterine cervix in producing significantly lower pain scores over 30-120 minutes after hysteroscopy [55] as well as being better than 50 mg diclofenac for lower limb injury between 15 and 60 minutes [56]. Over four days there was no difference between three times daily ketoprofen $25 \mathrm{mg}$ or paracetamol $500 \mathrm{mg}$ plus codeine $60 \mathrm{mg}$ in the treatment of ankle sprains [57]. In patients with cancer who developed bone cancer pain of at least moderate intensity, and who had not previously been treated with a continuous regimen of opioids or NSAIDs in the previous 15 days, there was no difference between $25 \mathrm{mg}$ dexketoprofen and $10 \mathrm{mg}$ ketorolac over seven days [58].

\section{Multiple dose trials in arthritis}

Two trials tested dexketoprofen $25 \mathrm{mg}$ three times a day against ketoprofen $150 \mathrm{mg}$ daily and diclofenac $150 \mathrm{mg}$ daily in patients with established arthritis $[59,60]$ (Additional file 6). Both trials were randomised and double blind, all had quality scores of three or more of the maximum 5 points and at least 9 points on an OPVS. The trials had a flare design in which patients discontinued previous treatment. Over two or three weeks of treatment there were no differences between dexketoprofen and diclofenac at these doses [60], though dexketoprofen 75 mg daily was superior to ketoprofen $150 \mathrm{mg}$ daily [59].

\section{Overall comparison between dexketoprofen and ketoprofen}

The main comparisons between dexketoprofen and ketoprofen occurred within the dental trials and those in postsurgical pain. There were three other comparisons. One comparison of intravenous administration in renal colic showed no difference between dexketoprofen $50 \mathrm{mg}$ and ketoprofen $100 \mathrm{mg}$ [47]. Of the two oral comparisons there was no difference between dexketoprofen $12.5 \mathrm{mg}$ or $25 \mathrm{mg}$ and ketoprofen $50 \mathrm{mg}$ [54], while the one comparison between $25 \mathrm{mg}$ dexketoprofen with $50 \mathrm{mg}$ ketoprofen in arthritis showed better results for dexketoprofen [59].

\section{Adverse events}

Additional files 1, 2, 3, 4, 5, 6 records adverse events reported in the trials, in terms of the numbers of patients reporting at least one adverse event, all cause withdrawals, and withdrawal due to an adverse event. Adverse event reporting was generally poor. Because trials varied from single dose to three weeks duration, with different routes of administration, drug doses, comparators, and condition, sensible analysis of adverse events were not possible. Because adverse event withdrawal is a significant event, and attempt was made to examine adverse event withdrawal rates in trials where at least two doses of drug were given. Because the rate of adverse event withdrawals is likely to be a function of the number of doses given, these were split by relatively shorted duration studies predominantly less than two days (dental and postsurgical pain) and relatively longer studies predominantly more two days or longer (acute painful conditions, back pain, and arthritis) (Table 3 ).

The choice of two doses was simply because withdrawal is not really an option after a single dose and is unlikely to be recorded in the same was as in multiple dose studies.

In both comparisons dexketoprofen (all doses) provided the about half the total number of patients (Table 3 ). Adverse event withdrawal rates were low, at about $2 \%$ or below in dental and postsurgical pain, and somewhat higher in trials of longer duration. The adverse event withdrawal rate for dexketoprofen was not out of line with other drugs, though limited numbers prevented any firm conclusions, and statistical tests were not deemed sensible.

No serious adverse events, like gastrointestinal bleeding, myocardial infarction, or death, were reported in any trial. 
Table 3: Adverse event withdrawal rates in trials where at least two doses of drug were given

\begin{tabular}{lcccc}
\hline & \multicolumn{2}{c}{ Dental and postsurgical pain } & Other acute, back pain, arthritis \\
\cline { 2 - 5 } \multicolumn{1}{c}{ Drug } & Number of patients & Adverse event withdrawal (\%) & Number of patients & Adverse event withdrawal (\%) \\
\hline Placebo & 236 & 2.5 & & no data \\
Dexketoprofen & 652 & 1.8 & 844 & 3.2 \\
Ketoprofen & 301 & 1.3 & 152 & 7.9 \\
Diclofenac & 80 & 0.0 & 272 & 3.7 \\
Tramadol & 72 & 1.4 & 247 & 9.7 \\
Paracetamol + opioid & 100 & 0.0 & 167 & 1.2 \\
\hline
\end{tabular}

\section{Discussion}

This review found reports of 34 randomised trials of dexketoprofen, predominantly of sufficiently high reporting quality to avoid bias $[9,61]$. To be comprehensive any randomised trial was included, but only higher quality trials (randomised, double blind) were used to calculate NNTs. Almost half the trials and just over half the patients $(51 \%)$ were in trials that had not previously been published in full, and so this review doubles the amount of information previously available on dexketoprofen. Significant numbers of otherwise unpublished pain trials have been found before in systematic reviews [62,63].

Nearly all trials appeared to be valid as judged by quality scores and OPVS scores. The two arthritis trials, at three weeks, were considerably shorter than the current norm in arthritis trials, which now is $6-12$ weeks. The trials tended to be relatively small, with an average of 190 patients split between several treatment groups, and while they were sufficient to yield statistical results regarding the direction of any effect, they were not individually large enough to comment sensibly on its magnitude [16]. While 10 trials had group sizes of at least 100 patients, these were spread throughout the different conditions studied (Table 1).

The small size and generally short duration of the trials limits transfer of knowledge to clinical practice. The trials tell us about whether dexketoprofen is an analgesic. They do not tell us how best to use it in any particular painful condition.

Meta-analysis of all trials was not possible because of the differences between them in terms of painful condition being treated, dose and route of administration of dexketoprofen, duration of therapy, and outcomes reported. Vote counting only was possible, and this showed that all 12 trials with a placebo comparison showed dexketoprofen to be better than placebo, and that 29/30 trials showed dexketoprofen to be at least equivalent to an active comparator of known analgesic efficacy (Table 1).
The one area where meta-analysis was possible was that of single dose oral administration in dental and postsurgical pain (Table 2). Based on limited data there appeared to be a dose-response, with better (lower) NNTs with higher doses of dexketoprofen. The best general comparison with other analgesics probably comes from the dental pain model, because these trials are consistently conducted in very similar patients, using similar methods and outcomes, and tried and tested methods $[64,65]$. The NNT for dexketoprofen compared with placebo for at least $50 \%$ pain relief over 4-6 hours was 2.6, comparable to ibuprofen 200-600 mg (NNTs 2.2-2.8) and diclofenac $50 \mathrm{mg}$ (NNT 2.1), and better than paracetamol $1000 \mathrm{mg}$ (NNT 3.7) [64]. Limited numbers of patients for some of these drugs and doses make it invidious to push these comparisons too far, but at least it can be said that oral dexketoprofen $25 \mathrm{mg}$ is an effective analgesic according to present standards. As yet we do not have sufficient or consistent information across systematic reviews of single dose analgesics to make comparisons of duration of analgesia (median time to remedication, or percentage of patients remedicating in a fixed time, for instance), though this would be useful additional information [66].

There available evidence is that analgesia with dexketoprofen is equivalent to analgesia obtained with double the dose of ketoprofen. In single doses in acute pain, there is a hint even of superior analgesia than double dose ketoprofen (Figure 3, Table 2), and there is at least equivalence in three other trials.

Again, the varied nature of the studies precluded any formal meta-analysis of adverse events. What could be done was a descriptive analysis of adverse event withdrawals in trials with at least two doses of dexketoprofen. The split by relatively short term studies in dental and postsurgical pain, and somewhat longer studies in acute pain, back pain, and arthritis (Table 3) appeared to make sense, as withdrawal rates tended to be somewhat higher in the longer duration studies. Dexketoprofen adverse event withdrawals were not higher than other effective analgesics, based on the limited data available. 
No conclusions could be drawn about serious adverse events like serious gastrointestinal bleeding, cardiovascular events, or mortality. Gastrointestinal bleeding and cardiovascular events tend to occur at a rate of about $1 \%$ a year in randomised trials in arthritis [67]. Trials of dexketoprofen lasted only three weeks with arthritis, and barely a week with most trials. In that circumstance, the rate of a serious adverse event would be expected in about 1 in 5,000 patients ( 1 in 100 multiplied by 50), and only 3,200 patients were in trials other than dental or postsurgical pain. Additionally, a number of those trials were in patients substantially younger than those in arthritis trials, with substantially lower baseline risk, decreasing the potential risk even lower than 1 in 5,000. The absence of serious events should not, therefore, be taken as an absence of risk, because the quantity, type and duration of studies precludes any such conclusion.

\section{Conclusion}

This review doubles the amount of information available concerning analgesic efficacy of dexketoprofen. That efficacy was apparent in single dose in dental and postsurgical pain, where NNTs for at least 50\% pain relief over 4-6 hours compared with placebo were similar to other effective analgesics. In vote-counting, dexketoprofen was at least as effective as other analgesics in 29/30 trials. While adverse event withdrawal was not different between dexketoprofen and comparator analgesics, the different conditions and comparators studies precluded any formal analysis. The amount of exposure was limited, and no conclusions could be drawn about safety in terms of serious adverse events like gastrointestinal bleeding or cardiovascular events.

\section{Competing interests}

RAM has received research grants, consulting, or lecture fees from pharmaceutical companies, government sources, and charities. Neither author has any direct stock holding in any pharmaceutical company.

\section{Authors' contributions}

RAM the original concept, planning the study, searching, data extraction, writing, analysis, and preparing a manuscript; JB was involved with searching, data extraction, writing, analysis, and preparing a manuscript.

\section{Additional material}

\section{Additional file 1}

Trials of oral dexktoprofen in pain after third molar extraction pain. The file contains information on each included study, with reference, quality score, design, treatments, main results, and comments. Click here for file

[http://www.biomedcentral.com/content/supplementary/14726904-8-11-S1.pdf]

\section{Additional file 2}

Trials of oral and injected dexktoprofen in pain after surgery. The file contains information on each included study, with reference, quality score, design, treatments, main results, and comments.

Click here for file

[http://www.biomedcentral.com/content/supplementary/14726904-8-11-S2.pdf]

\section{Additional file 3}

Trials of injected dexktoprofen in pain of renal colic. The file contains information on each included study, with reference, quality score, design, treatments, main results, and comments.

Click here for file

[http://www.biomedcentral.com/content/supplementary/14726904-8-11-S3.pdf]

\section{Additional file 4}

Trials of intramuscular and oral dexktoprofen in acute back pain. The file contains information on each included study, with reference, quality score, design, treatments, main results, and comments.

Click here for file

[http://www.biomedcentral.com/content/supplementary/14726904-8-11-S4.pdf]

\section{Additional file 5}

Trials of oral dexktoprofen in gynaecological and other acute painful conditions. The file contains information on each included study, with reference, quality score, design, treatments, main results, and comments. Click here for file

[http://www.biomedcentral.com/content/supplementary/14726904-8-11-S5.pdf]

\section{Additional file 6}

Trials of oral dexktoprofen in arthritis. The file contains information on each included study, with reference, quality score, design, treatments, main results, and comments.

Click here for file

[http://www.biomedcentral.com/content/supplementary/14726904-8-11-S6.pdf]

\section{Acknowledgements}

Pain Research is supported in part by the Oxford Pain Research Trust, and this work was also supported by an unrestricted educational grant from Menarini Group. Neither organisation had any role in design, planning, execution of the study, or in writing the manuscript. The terms of financial support included freedom for authors to reach their own conclusions, and an absolute right to publish the results of their research, irrespective of any conclusions reached. Menarini did have the right to view the final manuscript before publication, and did so.

\section{References}

I. Hernández-Díaz S, García Rodríguez LA: Association Between Nonsteroidal Anti-inflammatory Drugs and Upper Gastrointestinal Tract Bleeding/Perforation: An Overview of Epidemiologic Studies Published in the 1990s. Arch Int Med 2000, 160:2093-2099.

2. Laporte JR, lbanez L, Vidal X, Vendrell L, Leone R: Upper gastrointestinal bleeding associated with the use of NSAIDs: newer versus older agents. Drug Saf 2004, 27:4I I-420.

3. Barbanoj MJ, Antonijoan RM, Gich I: Clinical pharmacokinetics of dexketoprofen. Clin Pharmacokinet 200I, 40:245-262. 
4. Herrero JF, Romero-Sandoval EA, Gaitan G, Mazario J: Antinociception and the new $\mathrm{COX}$ inhibitors: research approaches and clinical perspectives. CNS Drug Rev 2003, 9:227-252.

5. Barbanoj MJ, Gich I, Artigas R, Tost D, Moros C, Antonijoan RM, García ML, Mauleon D: Pharmacokinetics of dexketoprofen trometamol in healthy volunteers after single and repeated oral doses. Drugs 1998, 52(Suppl 5):24-45.

6. McEwen J, De Luca M, Casini A, Gich I, Barbanoj MJ, Tost D, Artigas $R$, Mauleon D: The effect of food and an antacid on the bioavaliablity of dexketoprofen trometamol. J Clin Pharmacol 1998, 38(Suppl I 2):33S-40S.

7. Mauleon D, Artigas R, García ML, Carganico G: Preclinical and clinical development of dexketoprofen. Drugs 1996, 52(Suppl 5):24-45.

8. Jadad AR, Moore RA, Carroll D, Jenkinson C, Reynolds DJ, Gavaghan $\mathrm{DJ}, \mathrm{McQuay} \mathrm{HJ}$ : Assessing the quality of reports of randomized clinical trials: is blinding necessary? Control Clin Trials 1996, I7:I-12.

9. Smith LA, Oldman AD, McQuay HJ, Moore RA: Teasing apart quality and validity in systematic reviews: an example from acupuncture trials in chronic neck and back pain. Pain 2000, 86: I19-132.

10. Cooper S, Max M, Portenoy R, Laska E: Single-dose analgesic studies: the upside and downside of assay sensitivity. New York: Raven Press; 1991:1 17-124.

II. Moore A, McQuay H, Gavaghan D: Deriving dichotomous outcome measures from continuous data in randomised controlled trials of analgesics: verification from independent data. Pain 1997, 69:127-130.

12. Moore A, McQuay H, Gavaghan D: Deriving dichotomous outcome measures from continuous data in randomised controlled trials of analgesics. Pain 1996, 66:229-237.

13. Moore A, Moore O, McQuay H, Gavaghan D: Deriving dichotomous outcome measures from continuous data in randomised controlled trials of analgesics: use of pain intensity and visual analogue scales. Pain 1997, 69:3।I-315.

14. Collins SL, Edwards J, Moore RA, Smith LA, McQuay HJ: Seeking a simple measure of analgesia for mega-trials: is a single global assessment good enough? Pain 200I, 91:189-194.

15. Moher D, Cook DJ, Eastwood S, Olkin I, Rennie D, Stroup DF: Improving the quality of reports of meta-analyses of randomised controlled trials: the QUOROM statement. Quality of Reporting of Meta-analyses. Lancet 1999, 354:1896-1900.

16. Moore RA, Gavaghan D, Tramer MR, Collins SL, McQuay HJ: Size is everything - large amounts of information are needed to overcome random effects in estimating direction and magnitude of treatment effects. Pain 1998, 78:209-216.

17. Gavaghan DJ, Moore RA, McQuay HJ: An evaluation of homogeneity tests in meta-analyses in pain using simulations of individual patient data. Pain 2000, 85:415-424.

18. Higgins J, Thompson S, Deeks J, Altman D: Statistical heterogeneity in systematic reviews of clinical trials: a critical appraisal of guidelines and practice. J Health Serv Res Policy 2002, 7:5I-6I.

19. L'Abbe KA, Detsky AS, O'Rourke K: Meta-analysis in clinical research. Ann Intern Med 1987, 107:224-233.

20. Morris ], Gardner M: Calculating confidence intervals for relative risk, odds ratios and standardised ratios and rates. In Statistics with confidence - confidence intervals and statistical guidelines Edited by: Gardner M, Altman D. London: British Medical Journal; 1995:50-63.

21. Cook RJ, Sackett DL: The number needed to treat: a clinically useful measure of treatment effect. BM] 1995, 3 10:452-454.

22. Bagan JV, Lopez Arranz JS, Valencia E, Santamaria J, Eguidazu I, Horas M, Forns M, Zapata A, Artigas R, Mauleon D: Clinical comparison of dexketoprofen trometamol and dipyrone in postoperative dental pain. J Clin Pharmacol 1998, 38( 12 Suppl):55S-64S

23. Berini $L$ : Clinical trial to assess the analgesic efficacy of a single oral administration of LM-II58.TRIS in the prevention of post-operative pain. Clinical Trial Report 1999.

24. Gay C, Planas E, Donado M, Martinez J, Artigas R, Torres F, Mauleon $D$, Carganico G: Analgesic efficacy of low doses of dexketoprofen in the dental pain model. Clin Drug Invest 1996, I I:320-330.

25. Harrison F: Double-blind randomised, parallel-group comparison of the safety and efficacy of single oral doses of LMI I58.tris (dexketoprofen tromethamine salt, $12.5 \mathrm{mg}$ or 25 $\mathrm{mg}$ ) to placebo in patients with moderate to severe dental pain due to removal of impacted third molar teeth. Clinical Trial Report 1996

26. Jackson ID, Heidemann BH, Wilson J, Power I, Brown RD: Doubleblind, randomized, placebo-controlled trial comparing rofecoxib with dexketoprofen trometamol in surgical dentistry. Br J Anaesth 2004, 92:675-680.

27. Jimenez-Martinez E, Gasco-Garcia C, Arrieta-Blanco JJ, Gomez del Torno J, Bartolome Villar B: Study of the analgesic efficacy of Dexketoprofen Trometamol $25 \mathrm{mg}$. vs. Ibuprofen $600 \mathrm{mg}$. after their administration in patients subjected to oral surgery. Med Oral 2004, 9: I38-I 48.

28. McGurk M, Robinson P, Rajayogeswaran V, De Luca M, Casini A, Artigas R, Munoz G, Mauleon D: Clinical comparison of dexketoprofen trometamol, ketoprofen, and placebo in postoperative dental pain. I Clin Pharmacol 1998, 38( 12 Suppl):46S-54S.

29. Munoz G, Berini L, Sanchez S, Planas E, Forns M, Artigas R: Preoperative dexketoprofen trometamol for the prevention of postoperative dental pain: a randomised double-blind clinical trial. Method Find Exp Clin Pharmacol 1998, 20(Suppl A):69.

30. Zippel $\mathrm{H}$, Wagenitz $\mathrm{A}$ : Comparison of the efficacy and safety of intravenously administered dexketoprofen trometamol and ketoprofen in the management of pain after orthopaedic surgery: A multicentre, double-blind, randomised, parallelgroup clinical trial. Clin Drug Investig 2006, 26:517-528.

31. Zapata A, Cegarra F, Artigas R, Keller F: Dexketoprofen vs tramadol: randomised double-blind trial in patients with postoperative pain. British J Clin Pharmacol 2000, 223:. (abs 870)

32. Vidal F, Martinez $P$, Montero A, al e: Clinical trial to assess the analgesic efficacy and safety of LM-II58.TRIS (I 2.5 and 25 $\mathrm{mg}$ tid) versus ketoprofen $(50 \mathrm{mg}$ tid) and placebo after oral administration in patients with acute post-surgery pain. Clinical Trial Report 1999.

33. Schreiber M: Comparison of efficacy and tolerability of oral adminstration of $\mathbf{2 5} \mathbf{~ m g}$ dexketoprofen (trometamol) vs. 50 mg tramadol in patients with post-operative pain. Clinical Trial Report 1998.

34. Schreiber M: Double-blind, randomised, parallel-group comparison of the safety and efficacy of single oral doses of dexketoprofen tromethamine salt (LM- I I 58.tris, $12.5 \mathrm{mg}$ or $25 \mathrm{mg}$ ) with racemic ketorpofen $(50 \mathrm{mg})$ and placebo in patients with moderate to severe pain following orthopaedic surgery. Clinical Trial Report 1996.

35. Puig MM: Multicentre clinical trial to assess the efficacy and safety of dexketoprofen trometamol ( $25 \mathrm{mg}$ and $50 \mathrm{mg}$ bid) versus diclofenac ( $75 \mathrm{mg}$ bid) by the intramuscular route in the treatment of postoperative pain. Clinical Trial Report 2000.

36. Perez A: A multicentre clinical trial evaluating the analgesic efficacy and safety of dexketoprofen trometamol ( $25 \mathrm{mg} \mathrm{tid})$ versus diclofenac $(50 \mathrm{mg}$ tid) for the treatment of pain subsequent to ambulatory surgery. Clinical Trial Report 2002.

37. Peat SJ: Double blind, randomised, parallel group study of the safety, efficacy and influence on morphine usage of intravenous dexketoprofen trometamol $(50 \mathrm{mg})$ in comparison to intravenous tramadol $(100 \mathrm{mg})$ or placebo in the relief of pain following orthopaedic surgery. Clinical Trial Report 2000.

38. Latariet J: A comparative study on safety and efficacy of dexketoprofen trometamol versus paracetamol codeine (Dafalgan Codeine) in the treatment of moderate to severe pain in the post-operative follow-up of hip-replacement surgery. Clinical Trial Report 1998.

39. Iohom G, Walsh M, Higgins G, Shorten G: Effect of perioperative administration of dexketoprofen on opioid requirements and inflammatory response following elective hip arthroplasty. $\mathrm{Br}$ J Anaesth 2002, 88:520-526.

40. Hanna MH, Elliott KM, Stuart-Taylor ME, Roberts DR, Buggy D, Arthurs G]: Comparative study of analgesic efficacy and morphine-sparing effect of intramuscular dexketoprofen trometamol with ketoprofen or placebo after major orthopaedic surgery. Br J Clin Pharmacol 2003, 55:126-133.

4l. Berti M, Albertin A, Casati A, Palmisano S, Municino G, da Gama Malcher M, De Ponti A: A prospective, randomized comparison of dexketoprofen, ketoprofen or paracetamol for postoperative analgesia after outpatient knee arthroscopy. Minerva Anestesiol 2000, 66(7-8):549-554.

42. Harrison F: Double-blind randomised, parallel-group comparison of the safety and efficacy of oral dexketoprofen $25 \mathrm{mg}$ 
with tramadol $50 \mathrm{mg}$ in subjects with moderate to severe pain following orthopaedic surgery. Clinical Trial Report 200I.

43. Tuncer S, Tavlan A, Köstekçi H, Reisli R, Otelcioğlu S: Postoperatif ağrida deksketoprofen kullanimi. Agri 2006, 18:30-35.

44. Tramer M, Moore A, McQuay H: Omitting nitrous oxide in general anaesthesia: meta-analysis of intraoperative awareness and postoperative emesis in randomized controlled trials. $\mathrm{Br}$ J Anaesth 1996, 76:186-193.

45. Sanchez-Carpena J, Sesma-Sanchez J, Sanchez-Juan C, Tomas-Vecina S, Garcia-Alonso D, Rico-Salvado J, Forns M, Mas M, Paredes I, Artigas $\mathrm{R}$ : Comparison of dexketoprofen trometamol and dipyrone in the treatment of renal colic. Clin Drug Invest 2003, 23:139-152.

46. Sanchez-Carpena J, Dominguez-Hervella F, Garcia I, Gene E, Bugarin R, Martin A, Tomas-Vecina S, Garcia D, Serrano JA, Roman A, Mariné M, Mosteiro ML, Dexketoprofen Renal Colic Study Group: Comparison of intravenous dexketoprofen and dipyrone in acute renal colic. Eur J Clin Pharmacol 2007, 63(8):75I-760.

47. Debre B: A double-blind (observer blind), randomised trial comparing the analgesic efficacy and safety of dexketoprofentrometamol $(50 \mathrm{mg})$ with ketoprofen $(100 \mathrm{mg})$ given as an intravenous infusion, in patients with renal or uretal colic. Clinical Trial Report 2000.

48. Zippel H, Wagenitz A: A multicentre, randomised, double-blind study comparing the efficacy and tolerability of intramuscular dexketoprofen versus diclofenac in the symptomatic treatment of acute low back pain. Clin Drug Investig 2007, 27:533-543.

49. Kubler U: Comparative clinical trial of the efficacy and tolerability of $\mathbf{2 5} \mathbf{~ m g}$ dexketoprofen tid versus $\mathbf{5 0} \mathbf{~ m g}$ tramadol tid in patients with acute lumbago of at least moderate severity. Clinical Trial Report 1999.

50. Metscher B, Kubler U, Jahnel-Kracht H: [Dexketoprofen-trometamol and tramadol in acute lumbago]. Fortschr Med Orig 200I, I I 8: |47-|5|.

5I. Granados J: Clinical trial to assess the efficacy and safety of LM-I I 58.tris $(25 \mathrm{mg}$ t.i.d) versus diclofenac $(50 \mathrm{mg}$ t.i.d) for the symptomatic treatment of patients with acute lumbar pain. Clinical Trial Report.

52. Castiaux: Comparative, multicentre, randomised, doubleblind, parallel-group trial on the efficacy and tolerability of dexketoprofen trometamol versus tramadol $50 \mathrm{mg}$ t.i.d in a 7-day treatment of acute low back pain. Clinical Trial Report 1999.

53. Bourgeois P: Multicentre, comparative double blind study of dexketoprofen trometamol $25 \mathrm{mg}$ versus Di-antalvic in the treatment of acute low back pain. Clinical Trial Report 1999.

54. Ezcurdia M, Cortejoso FJ, Lanzon R, Ugalde FJ, Herruzo A, Artigas R, Fernandez F, Torres F, Mauleon D: Comparison of the efficacy and tolerability of dexketoprofen and ketoprofen in the treatment of primary dysmenorrhea. J Clin Pharmacol 1998, 38(I 2 Suppl):65S-73S.

55. Mercorio F, De Simone R, Landi P, Sarchianaki A, Tessitore G, Nappi $\mathrm{C}$ : Oral dexketoprofen for pain treatment during diagnostic hysteroscopy in postmenopausal women. Maturitas 2002, 43:277-28I.

56. Leman P, Kapadia Y, Herington J: Randomised controlled trial of the onset of analgesic efficacy of dexketoprofen and diclofenac in lower limb injury. Emerg Med J 2003, 20:5 I I-5 I3.

57. Keller F: Multicentre, double-blind study to evaluate the efficacy and safety of oral dexketoprofen trometamol in comparison to paracetamol-codeine in the treatment of ankle sprains. Clinical Trial Report 1999.

58. Rodriguez MJ, Contreras D, Galvez R, Castro A, Camba MA, Busquets $C$, Herrera I: Double-blind evaluation of short-term analgesic efficacy of orally administered dexketoprofen trometamol and ketorolac in bone cancer pain. Pain 2003, 104: 103-II0.

59. Beltran J, Martin-Mola E, Figueroa M, Granados J, Sanmarti R, Artigas R, Torres F, Forns M, Mauleon D: Comparison of dexketoprofen trometamol and ketoprofen in the treatment of osteoarthritis of the knee. J Clin Pharmacol 1998, 38(I 2 Suppl):74S-80S.

60. Marenco JL, Pérez M, Navarro FJ, FMartínez FG, Beltrán J, Salvatierra D, Alonso A, Ballarín M, Eguidazu I, Zapata A, Horas M, Torres F, Artigas R, Mauleón D: A multicentre, randomised, double-blind study to compare the efficacy and tolerability of dexketopro- fen trometamol versus diclofenac in the symptomatic treatment of knee osteoarthritis. Clin Drug Invest 2000, 19:247-256.

61. Khan KS, Daya S, Jadad A: The importance of quality of primary studies in producing unbiased systematic reviews. Arch Intern Med 1996, 156:661-666.

62. Moore RA, McQuay HJ: Single-patient data meta-analysis of 3453 postoperative patients: oral tramadol versus placebo, codeine and combination analgesics. Pain 1997, 69:287-294.

63. Moore RA, Tramèr MR, Carroll D, Wiffen PJ, McQuay HJ: Quantitative systematic review of topically applied non-steroidal anti-inflammatory drugs. $B M J$ 1998, 316:333-338.

64. Barden J, Edwards JE, McQuay HJ, Wiffen PJ, Moore RA: Relative efficacy of oral analgesics after third molar extraction. $\mathrm{Br}$ Dent J 2004, 197:407-4II.

65. Moore R, Edwards J, Barden J, McQuay H: Bandolier's Little Book of Pain Oxford: Oxford University Press; 2003.

66. Moore R, Edwards J, McQuay H: Acute pain: Individual patient meta-analysis shows the impact of different ways of analysing and presenting results. Pain 2005, I 16:322-331.

67. Moore RA, Derry S, McQuay HJ: Cyclo-oxygenase-2 selective inhibitors and nonsteroidal anti-inflammatory drugs: balancing gastrointestinal and cardiovascular risk. BMC Musculoskelet Disord 2007, 8:73.

\section{Pre-publication history}

The pre-publication history for this paper can be accessed here:

http://www.biomedcentral.com/1472-6904/8/11/prepub
Publish with BioMed Central and every scientist can read your work free of charge

"BioMed Central will be the most significant development for disseminating the results of biomedical research in our lifetime. "

Sir Paul Nurse, Cancer Research UK

Your research papers will be:

- available free of charge to the entire biomedical community

- peer reviewed and published immediately upon acceptance

- cited in PubMed and archived on PubMed Central

- yours - you keep the copyright 